\title{
Cardiogenic shock after nifedipine administration in a pregnant patient: A case report and review of the literature
}

\author{
Ilaria Botta ${ }^{1,2}$, Jacques Devriendt ${ }^{2}$, Jose Castro Rodriguez ${ }^{1}$, Marielle Morissens ${ }^{1}$, \\ Andrew Carling ${ }^{3}$, Leonel Barreto Gutierrez ${ }^{2}$, Thierry Preseau ${ }^{4}$, David De Bels ${ }^{2}$, \\ Patrick M. Honore ${ }^{2}$, Sebastien Redant ${ }^{2}$ \\ 'Department of Cardiology, Brugmann University Hospital, \\ Université Libre de Bruxelles, Brussels, Belgium; \\ ${ }^{2}$ Department of Intensive Care Medicine, Brugmann University Hospital, \\ Université Libre de Bruxelles, Brussels, Belgium; \\ ${ }^{3}$ Department of Obstetrics, Brugmann University Hospital, \\ Université Libre de Bruxelles, Brussels, Belgium; \\ ${ }^{4}$ Department of Emergency Medicine, Brugmann University Hospital, \\ Université Libre de Bruxelles, Brussels, Belgium
}

Address for Correspondence: Dr. Sebastien Redant, MD, ICU Resident, Brugmann University Hospital,

Place Arthur Van Gehuchtenplein, 4,

Brussels, Belgium.

E-mail:

Sebastien.Redant@CHU-Brugmann.be

Prof. Patrick M. Honore, MD, PhD, FCCM, Co-Director of ICU Department, Brugmann University Hospital, Place Arthur Van Gehuchtenplein, 4, Brussels, Belgium

E-mail:

Patrick.Honore@CHU-Brugmann.be

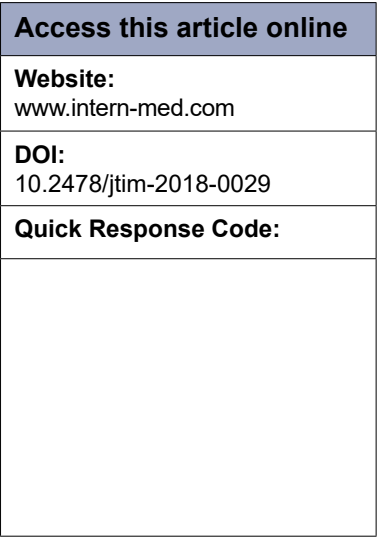

\section{ABSTRACT}

We present a case of a 21-year-old Caucasian woman at 27 weeks of pregnancy who was admitted to the obstetric department for pre-term labor. She received $10 \mathrm{mg}$ of nifedipine 4 times in $1 \mathrm{~h}$, according to the internal protocol. Shortly after, she brutally deteriorated with pulmonary edema and hypoxemia requiring transfer to the intensive care unit (ICU) for mechanical ventilation. She finally improved and was successfully extubated after undergoing a percutaneous valvuloplasty of the mitral valve. This case illustrates a severe cardiogenic shock after administration of nifedipine for premature labor in a context of unknown rheumatic mitral stenosis. Nifedipine induces a reflex tachycardia that reduces the diastolic period and thereby precipitates pulmonary edema in case of mitral stenosis. This case emphasizes the fact that this drug may be severely harmful and should never be used before a careful physical examination and echocardiography if valvular heart disease is suspected.

Key words: nifedipine, pregnancy, mitral stenosis, pulmonary edema

\section{INTRODUCTION}

Nifedipine is a calcium-channel blocker that has been used as tocolytic agent for decades. This medication blocks the influx of calcium through the cell membrane, inhibits the release of intracellular calcium from the sarcoplasmic reticulum, and enhances calcium efflux from the cell. The resulting low intracellular concentration inhibits the myosin light-chain kinase phosphorylation, leading to myometrial relaxation. Calciumchannel blockers, specially nifedipine, have been proven to be more effective in prolonging pregnancy with fewer secondary effects than betamimetics. ${ }^{[1-5]}$ Maternal serious adverse events have been described in case reports. ${ }^{[6-11]}$ We present the case of a 21-year-old woman who developed a severe cardiogenic choc after the administration of nifedipine.

\section{CASE REPORT}

A 21-year-old Caucasian woman at 27 weeks of pregnancy was admitted to the obstetric department for pre-term labor. She received $10 \mathrm{mg}$ of nifedipine 4 times in $1 \mathrm{~h}$, according to the internal protocol. Shortly after, she brutally deteriorated with pulmonary edema and hypoxemia requiring transfer to the intensive care unit (ICU).

At the admission in the ICU, her blood pressure was 101/61 $\mathrm{mm} \mathrm{Hg}(\mathrm{MAP}=72)$, ECG revealed a sinus tachycardia $(142$ bpm), and oxygen saturation was $98 \%$ under 100\% high flow oxygenation. Physical 
examination revealed a loud first heart sound, diastolic murmur, bilateral wheezing, and jugular venous distension.

The clinical situation rapidly deteriorated with a fall in systolic blood pressure and a worsening desaturation (78\%) with metabolic acidosis and hyperlactatemia (34 $\mathrm{mg} / \mathrm{dL}$ ). The patient was intubated and ventilated (volumecontrolled ventilation with $\mathrm{FiO}_{2} 100 \%$ and PEEP at 15 $\mathrm{cm}$ of $\mathrm{H}_{2} \mathrm{O}$ ). Chest X-ray confirmed pulmonary edema.

Cardiac echography revealed unknown severe mitral stenosis (Figure 1a and b) with normal left ventricular function, enlargement and pressure overload of the left atrium, and severe pulmonary hypertension [estimated pulmonary systolic arterial pressure $(\mathrm{PAP})=85 \mathrm{~mm} \mathrm{Hg}$.

The diagnosis was a cardiogenic shock precipitated by administration of nifedipine in a pregnant woman with unknown severe mitral stenosis.

Loop diuretics (furosemide) and full-dose heparin were administered once blood pressure was stabilized. Ultrasound examination showed no fetal distress. Transoesophageal echocardiography showed a severe rheumatic mitral stenosis with an estimated valve area of $0.5 \mathrm{~cm}^{2}$ and a transmitral mean gradient of $25 \mathrm{~mm}$ Hg. The Wilkins score was 8, authorizing percutaneous valvuloplasty. $\cdot^{[12]}$

However, soon after admission, spontaneous vaginal delivery occurred, before the valvuloplasty start.

The baby was alive and transferred to intensive neonatal care unit. The mother remained in a critical state with hypotension and needed ventilation despite the delivery.

Even more, the delivery was complicated by an endometritis

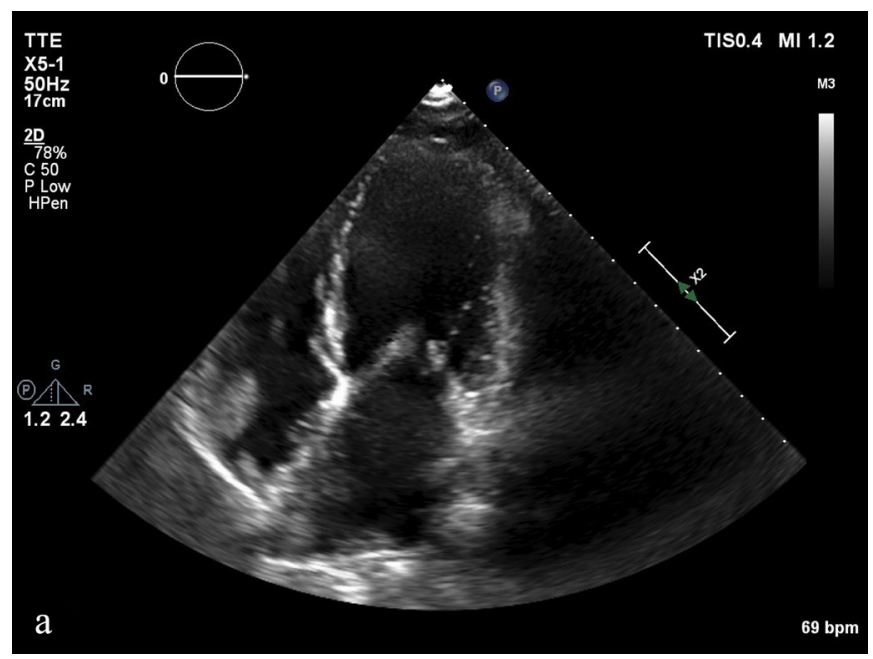

with sepsis treated by ceftriaxone and ampicillin, so that valvuloplasty had to be postponed.

On day 8 , after resolution of the infection, a percutaneous double balloon mitral valvuloplasty was performed with a good result (Figures 2 and 3). Mitral mean gradient was reduced from 10 to $3 \mathrm{mmHg}$, the mitral area was increased from 0.5 to $1.65 \mathrm{~cm}^{2}$, and pulmonary pressure was normalized (Figure $4 \mathrm{a}$ and b).

After valvuloplasty, the recovery was rapid and the patient could be extubated the day after.

\section{DISCUSSION}

Tocolytics are frequently used to delay delivery. Because of limited available data, there is no recommendations or guidelines regarding the use of maternal tocolytics aimed at improving outcomes of the babies. ${ }^{[13,14]}$ When tocolysis is required (for in utero transfer or pulmonary maturation), nifedipine is the drug of choice. ${ }^{[14]}$ But nowadays nifedipine is not approved by the FDA for tocolytic use. Today, the use is based on studies with insufficient data about safety. ${ }^{[15-16]}$ Hemodynamic effects are variable in the literature. Luewan et al. found $17.8 \%$ and $17.2 \%$ of systolic and diastolic hypotension, respectively (fall of $15 \mathrm{~mm} \mathrm{Hg}$ or more). In $3.2 \%$ of woman, they found systolic blood pressure under $90 \mathrm{~mm} \mathrm{Hg}$, and $3.8 \%$ had a diastolic blood pressure under $60 \mathrm{~mm} \mathrm{Hg} .{ }^{[6]}$ Yamasato et al. observed tachycardia in 37.3\% at 20-60 min after intake. ${ }^{[7]}$

In the literature evaluated by Khan et al., there was no maternal death but 85 of the fetal death attributed to the use of calcium-channel blocker, whereas $51 \%$ were associated with nifedipine. ${ }^{[16]}$ Maternal serious adverse event are reported in case reports. ${ }^{[6-11]}$ Some authors

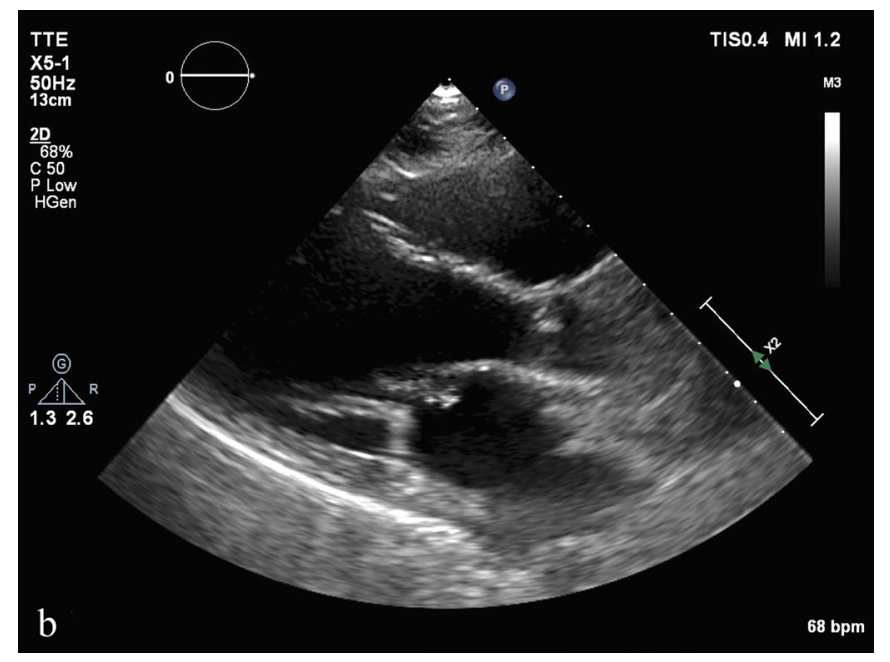

Figure 1: Echocardiography before valvulosplasty. (a) Apical view and (b) paravalvular view 


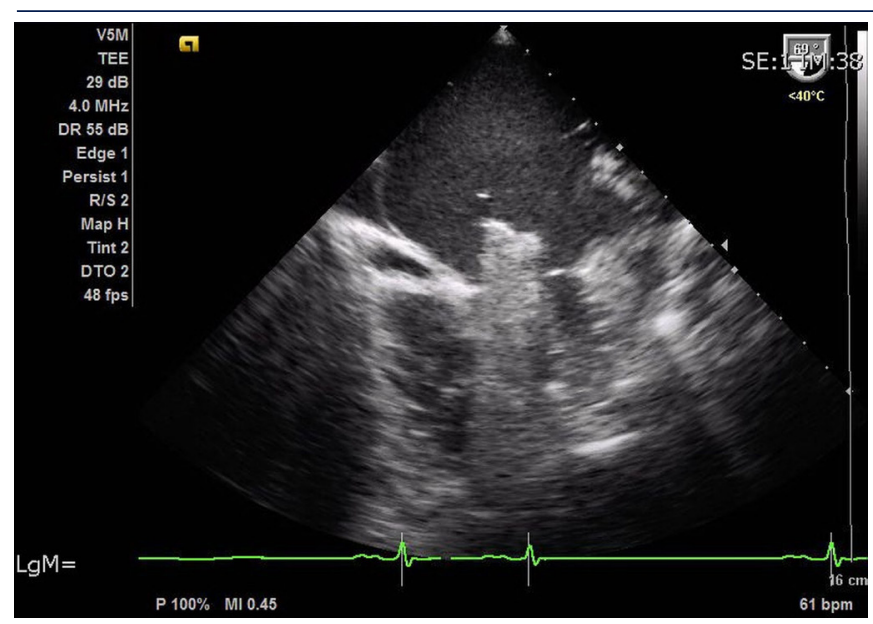

Figure 2: Echocardiography during procedure: Insertion of double balloon

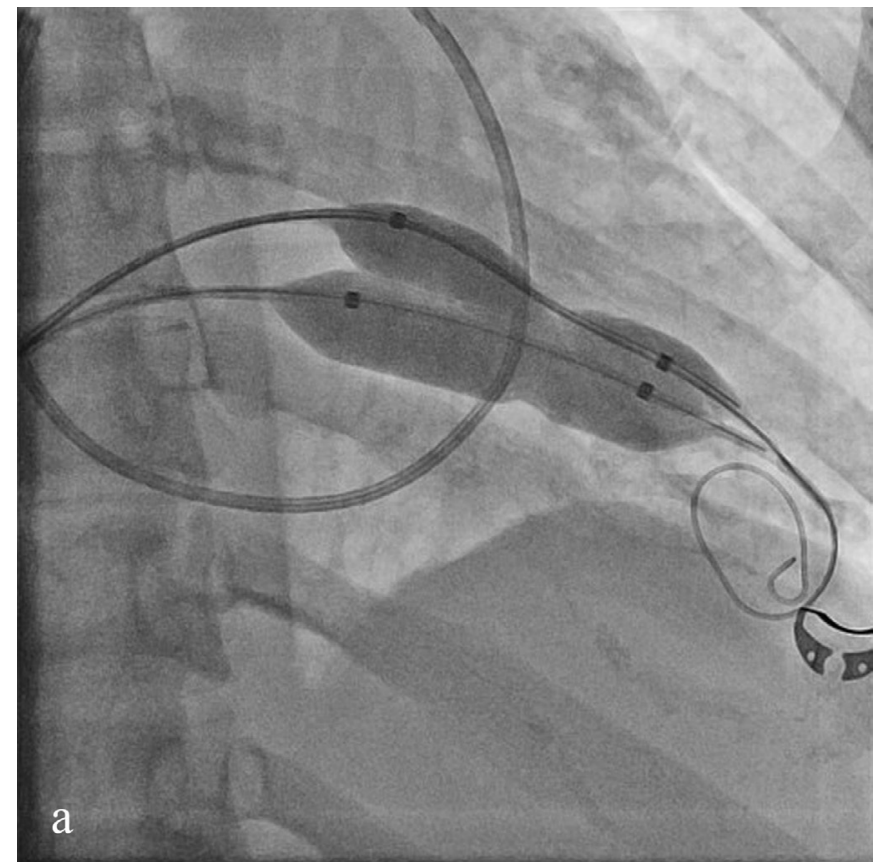

Figure 3: Angiography of the double balloon during valvuloplasty. (a) Deflated balloon insertion before valvuloplasty and (b) dilated balloon.
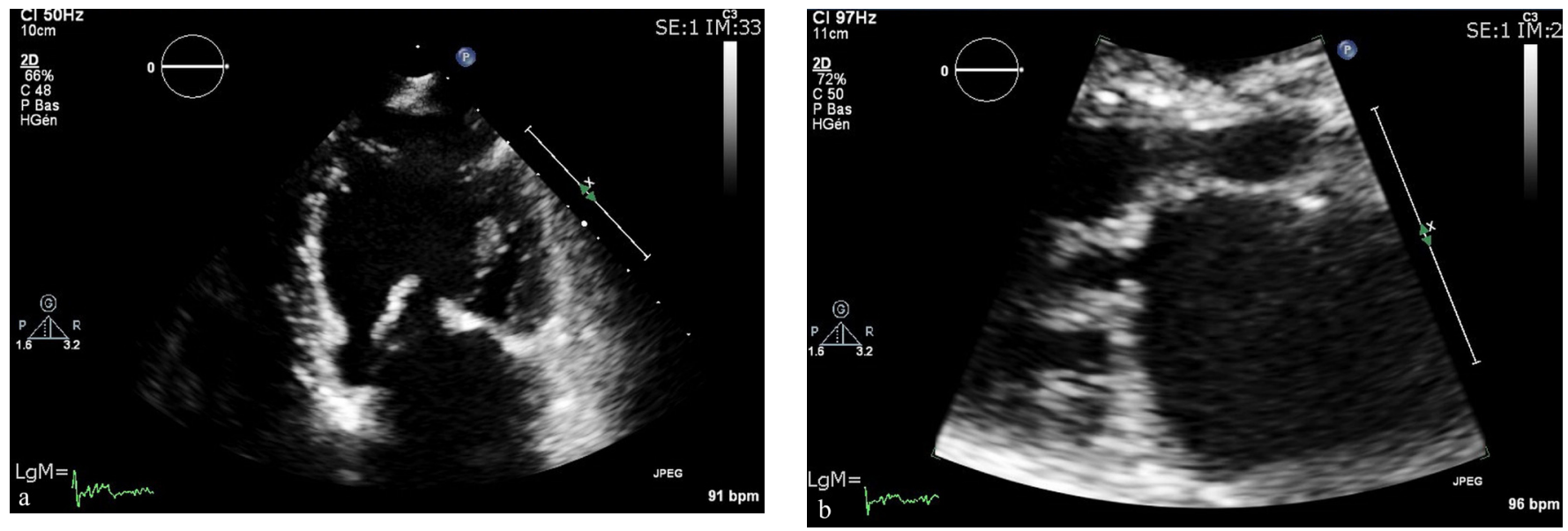

Figure 4: Echocardiography after valvulosplasty. (a): Apical view and (b) parasternal view 
valvular heart disease, whereas in developing countries, rheumatic valvular disease remains the leading cause. ${ }^{[20]}$ In many patients with significant valvular heart disease, the diagnosis is unknown before pregnancy and the pathology is revealed by the hemodynamic burden of pregnancy. ${ }^{[21]}$ In mitral stenosis, heart failure occurs frequently in the second and third trimesters in previously asymptomatic patients. The rate of prematurity is $20-30 \%$ and rate of stillbirth is $1-3 \% .^{[22]}$ The treatment of choice during pregnancy is percutaneous balloon mitral valvuloplasty, with fewer fetal complications when compared to surgery ${ }^{[23]}$ and an improvement in the New York Heart Association (NYHA) status by at least one class in $80 \%$ of the cases. ${ }^{[2,25]}$ The average estimated radiation energy for balloon mitral valvuloplasty is $0.2 \mathrm{rad}$, which is far lower than the 5-rad level under which radiation is considered to be safe. ${ }^{[26]}$ The indication for balloon mitral valvuloplasty during pregnancy is a patient with a refractory heart failure, a mild mitral regurgitation, a suitable morphology, and the absence of left atrial thrombus. ${ }^{[23]}$ Nitric oxide is only a measure to buy time in order to realize in better conditions the balloon mitral valvulosplasty. ${ }^{[27,28]}$

In our patient, cardiogenic shock was precipitated by nifedipine, which induced hypotension and reflex tachycardia. Tachycardia and vasodilatation are very harmful in mitral stenosis.

\section{CONCLUSION}

We present a case of a 21-year-old pregnant woman who developed a severe cardiogenic shock after the administration of nifedipine for premature labor in the context of unknown rheumatic mitral stenosis. This case emphasizes the fact that this drug may be severely harmful and should never be used before a careful physical examination and echocardiography if valvular heart disease is suspected.

\section{Conflict of Interest}

There is no conflict of interest.

\section{REFERENCES}

1. King JF, Flenady V, Papatsonis D, Dekker G, Carbonne B. Calcium channel blockers for inhibiting preterm labor, a systematic review of the evidence and a protocol for administration of nifedipine. Aust $\mathrm{N} \mathrm{Z}$ J Obstet Gynaecol 2003; 43: 192-8.

2. Weerakul W, Chittacharoen A, Suthutvoravut S. Nifedipine versus terbutaline in management of preterm labor. Int J Gynaecol Obstet 2002; 76: 311-3.

3. Papatsonis DN, Van Geijn HP, Adèr HJ, Lange FM, Bleker OP, Dekker GA. Nifedipine and Ritodrine in the management of preterm labor: a randomized multicenter trial. Obstet Gynecol 1997; 90: 230-4.

4. Cararach V, Palacio M, Martínez S, Deulofeu P, Sánchez M, Cobo T, et al. Nifedipine versus ritodrine for suppression of preterm labor. Comparison of their efficacy and secondary effects. Eur J Obstet Gynecol Reprod Biol 2006; 127: 204-8.

5. Bracero LA, Leikin E, Kirshenbaum N, Tejani N. Comparison of nifedipine and ritodrine for the treatment of preterm labor. Am J Perinatol 1991; 8: 365-9.

6. Luewan S, Mahatep R, Tongsong T. Hypotension in normotensive pregnant women treated with nifedipine as a tocolytic drug. Arch Gynecol Obstet 2011; 284: 527-30.

7. Yamasato K, Burlingame J, Kaneshiro B. Hemodynamic effects of nifedipine tocolysis. Obstet Gynaecol Res 2015; 41: 17-22.

8. Vast P, Dubreucq-Fossaert S, Subtil D. Acute pulmonary oedema during nicardipine therapy for premature labour. Report of five cases. Eur J Obstet Gynecol Reprod Biol 2004; 113: 98-9.

9. Bal L, Thierry S, Brocas E, Adam M, Van de Louw A, Tenaillon A. Pulmonary oedema induced by calcium-channel blockade for tocolysis. Anesth Analg 2004; 99: 910-1.

10. Oei SG, Oei SK, Brolmann H. Myocardial infarction during nifedipine therapy for preterm labor. N Engl J Med 1999; 340: 154.

11. Verhaert D, Van Acker R. Acute myocardial infarction during pregnancy. Acta Cardiol 2004; 59: 331-9.

12. Wilkins GT, Weyman AE, Abascal VM, Block PC, Palacios IF. Percutaneous balloon dilatation of the mitral valve: an analysis of echocardiographic variables related to outcome and the mechanism of dilatation. Br Heart J 1988; 60:299-308.

13. World Health Organization. WHO recommendations on interventions to improve preterm birth outcomes. Geneva: World Health Organization, 2015. Available at: http://www.who.int/reproductivehealth/publications/maternal_perinatal_health/preterm-birth-guideline. Accessed on August 23, 2018.

14. Vogel JP, Oladapo OT, Manu A, Gülmezoglu AM, Bahl R. New WHO recommendations to improve the outcomes of preterm birth. Lancet Glob Health 2015; 3: e589-90.

15. Lamont RF, Khan KS, Beattie B, Cabero Roura L, Di Renzo GC, Dudenhausen JW, et al. The quality of nifedipine studies used to assess tocolytic efficacy: a systematic review. J Perinatol Med 2005; 33: 287-95.

16. Khan K, Zamora J, Lamont RF, Van Geijn Hp H, Svare J, Santos-Jorge C, et al. Safety concerns for the use of calcium channel blockers in pregnancy for the treatment of spontaneous preterm labour and hypertension: a systematic review and meta-regression analysis. J Matern Fetal Neonatal Med 2010; 23: 1030-8.

17. Beattie R, Hlmer H, Van Geijn H. Emerging issues over the choice of nifedipine, beta agonists and atosiban for tocolysis in spontaneous preterm labour-a proposed systematic review by the international preterm labor council. J Obstet Gynaecol 2004; 24: 213-5.

18. Van Geijn, Lenglet J, Bolte A. Nifedipine trials: effectiveness and safety aspect. BJOG 2005; 112: S79-83.

19. Suchaya L, Rathasart M, Theera T. Hypotension in normotensive pregnant women treated with nifedipine as tocolytic drug. Arch Gynecol Obstet 2011; 284: 527-30.

20. Samiei N, Amirsardari M, Rezaei Y, Parsaee M, Kashfi F, Hantoosh Zadeh $\mathrm{S}$, et al. Echocardiographic Evaluation of Hemodynamic Changes in LeftSided Heart Valves in Pregnant Women With Valvular Heart Disease. Am J Cardio 2016; 118: 1046-52.

21. Anthony J, Osman O, Sani MU. Valvular heart disease in pregnancy. Cardiovasc J Afr 2016; 27: 111-8.

22. Nanna M, Stergiopoulos K. Pregnancy complicated by valvular heart disease: an update. J Am Heart Assoc 2014; 3: 1-18.

23. de Souza JA, Martinez EE Jr, Ambrose JA, Alves CM, Born D, Buffolo $\mathrm{E}$, et al. Percutaneous balloon mitral valvuloplasty in comparison with open mitral valve commissurotomy for mitral stenosis during pregnancy. J Am Coll Cardiol 2001; 37: 900-3.

24. Vinayakumar D, Vinod GV, Madhavan S, Krishnan MN. Maternal and fetal outcomes in pregnant women undergoing balloon mitral valvotomy for rheumatic mitral stenosis. Indian Heart J 2016; 68: 780-2. 
25. de Andrade J, Maldonado M, de Souza J. The role of mitral balloon valvuloplasty in the treatment of rheumatic mitral valve stenosis during pregnancy. Rev Esp Cardiol 2001; 54: 573-9.

26. Routray SN, Mishra TK, Swain S, Patnaik UK, Behera M. Balloon mitral valvuloplasty during pregnancy. Int J Gynaecol Obstet 2004; 85: 18-23.

27. Juul N. Inhaled nitric oxide in a pregnant woman with pulmonary hypertension and critical aortic and mitral stenosis. Chest 2014; 145: S509a.
28. Mahoney P, Loh E, Herrmann H. Hemodynamic effects of inhaled nitric oxide in women with mitral stenosis and pulmonary hypertension. Am J Cardiol 2001; 87: 188-92.

How to cite this article: Botta I, Devriendt J, Castro Rodriguez J, Morissens M, Carling A, Barreto Gutierrez L, et al.. Cardiogenic shock after nifedipine administration in a pregnant patient: A case report and review of the literature. J Transl Intern Med 2018; 6: 152-6. 